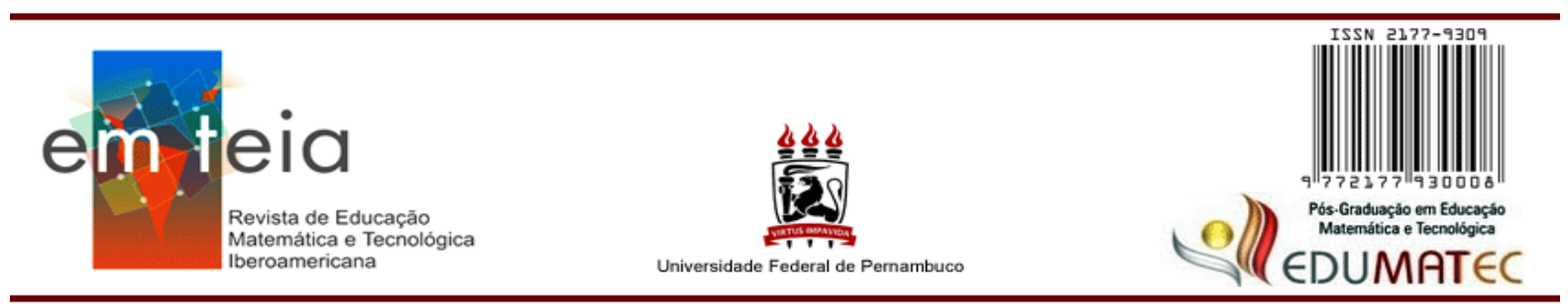

\title{
A HISTÓRIA DA MATEMÁTICA E A PRÁTICA DE DEMONSTRAÇÕES NA FORMAÇÃO DE PROFESSORES: TRAÇOS DO PROFMAT
}

\author{
HISTORY OF MATHEMATICS AND THE PRACTICE OF PROOF IN \\ TEACHER'S TRAINING: PROFMAT'S SIGNATURES
}

\author{
Ana Márcia Fernandes Tucci de Carvalho \\ Doutora em Educação Matemática \\ Universidade Estadual de Londrina - Paraná - BR \\ tucci@uel.br
}

Túlio Oliveira de Carvalho

Doutor em Ciências

Universidade Estadual de Londrina - Paraná - BR

\section{Resumo}

tulio.decarvalho@gmail.com

Trazemos considerações sobre a prática da demonstração formal na formação dos professores de Matemática, dentro da disciplina de História da Matemática, no âmbito do Profmat da Universidade Estadual de Londrina. O objetivo é investigar concepções do professor-aluno do Profmat sobre a demonstração matemática num contexto historicamente situado. A metodologia utilizada pautou-se no paradigma qualitativo, com a coleta de dados realizada através de atividades individuais e escritas. Participaram da pesquisa dez professores da Educação Básica, com tempo de magistério variado, cursistas do Profmat. Com relação ao conhecimento dos professores do Profmat sobre aspectos da prática de demonstrações, os registros escritos se explicam em dois níveis, um estrutural, relativo à grade curricular do Profmat; e outro conjuntural, relativo à circunstância da atividade ter sido aplicada na disciplina de História da Matemática.

Palavras-Chave: Profmat, História da Matemática, demonstrações, formação de Professores.

\begin{abstract}
This paper reports on the practice of formal proofs in the training of mathematics teachers, within the syllabus of History of Mathematics, in the Universidade Estadual de Londrina's Profmat program. The goal is to investigate Profmats teachers-students' conceptions on formal proof, given a historical context. We used a qualitative methodology, collecting data from individually written activities from ten subjects, teachers of basic educational level, with varying experience time, participants in Profmat program. With respect to the acquaintance of the teachers on aspects of formal proof practice, the written responses have two levels of explanation: one structural, referring to Profmat's curriculum, and the other conjunctural, conditioned by the circumstance of the History of Mathematics course.
\end{abstract}

Keywords: Profmat, History of Mathematics, proofs, teacher's training. 


\section{Introdução}

A Sociedade Brasileira de Matemática (SBM), em parceria com a Coordenação de Aperfeiçoamento de Pessoal de Nível Superior (Capes), criou, em outubro de 2010, o primeiro curso de pós-graduação stricto sensu semipresencial, dentre as políticas públicas brasileiras para a formação de professores de Matemática: o Mestrado Profissional em Matemática em Rede Nacional - Profmat.

De acordo com a SBM, no sítio oficial destinado ao programa, este é desenvolvido por diversas Instituições de Ensino Superior, no âmbito da Universidade Aberta do Brasil, sendo financiado parcialmente pela Capes. A coordenação geral do programa fica a cargo de representantes da Sociedade Brasileira de Matemática, com apoio do Instituto de Matemática Pura e Aplicada (Impa), com sede no Rio de Janeiro.

Ainda de acordo com o sítio oficial da SBM, um dos objetivos do Profmat é "proporcionar formação Matemática aprofundada e relevante ao exercício da docência na Educação Básica, visando dar ao egresso a qualificação certificada para o exercício da profissão de professor de Matemática" (SBM, 2017, s/p).

Dentro da grade curricular deste programa de Mestrado Profissional em Matemática, durante o segundo ano, após cursar as disciplinas consideradas básicas, os alunos matriculados fazem duas disciplinas eletivas, uma das quais pode ser História da Matemática.

Este artigo discute sobre potencialidades da disciplina de História da Matemática em se constituir como espaço privilegiado para a formação do professor de Matemática e para tratar um objeto matemático, a demonstração, visto como prática de um discurso, com matizes históricos.

Uma das acepções da palavra 'potencialidade' é "capacidade de realização, de produção, de execução" (HOUAISS; VILLAR, 2001, p. 2273). É neste sentido que propomos a avaliação das possibilidades e limitações do uso da disciplina de História da Matemática como contexto para explorar conhecimentos antigos e/ou apresentar conhecimentos novos para o professor. Nas palavras de Roque e Carvalho (2012, p. XIII), "uma consequência deste tipo de abordagem [...] é que o estudo da História pode ser uma ocasião para se aprender Matemática, ainda que seja uma Matemática distinta daquela que praticamos hoje”.

Mais especificamente, o objeto de estudo que investigamos foi: quais as concepções do professor aluno do Profmat sobre a demonstração matemática num contexto historicamente situado? 
Pautados por este questionamento, faremos considerações sobre os temas envolvidos: a formação de professores no Profmat e papéis da História da Matemática e das demonstrações em Matemática para esta formação, e, para dar base à pesquisa, apresenta-se um recorte de atividade realizada durante o desenvolvimento da disciplina de História da Matemática para uma turma deste mestrado profissional.

Apresentamos também os delineamentos da pesquisa, para a qual lançamos mão do paradigma qualitativo, com a utilização para a coleta de dados de atividades de natureza investigativa. Encerramos com a discussão dos resultados.

\section{Considerações sobre a formação do professor na perspectiva do Profmat}

Uma das metas do Profmat, como apresentado acima em um de seus objetivos, é trazer para o primeiro plano da atuação do professor "uma formação Matemática aprofundada" (SBM, 2017, s/p).

A questão passa a ser o sentido da palavra 'aprofundada', ou de outro modo, qual deve ser a Matemática que o professor de Matemática da Educação Básica deve conhecer? Este debate não é novo.

Moreira et al. (2005) fazem este questionamento, especificamente com relação à disciplina de Análise Real, ministrada no curso de Licenciatura em Matemática, inquirindo matemáticos. Recentemente, Moreira e Vianna (2016) retomam a temática, agora junto à comunidade de educadores matemáticos. Os autores concluem que, para ambos os grupos (de matemáticos e de educadores matemáticos), o conhecimento formal da disciplina “[...] é fundamental para que os licenciandos tenham um contato mínimo com a Matemática superior e possam construir um ponto de vista sobre a Matemática atual" (MOREIRA; VIANNA, 2016, p. 533) e apontam uma diferença entre os respectivos pontos de vista

o aluno da licenciatura precisa conhecer a natureza do pensamento matemático, a forma como a Matemática organiza-se em conhecimento específico, precisa ter uma cultura Matemática (Primeira Categoria [dos matemáticos]). Num segundo conjunto de argumentos, ambos os grupos defendem a obrigatoriedade da disciplina na licenciatura porque ela traria um aprofundamento dos conhecimentos matemáticos ao licenciando. Este conhecimento seria necessário para que o futuro professor pudesse perceber problemas epistemológicos importantes nas abordagens usuais dadas a conceitos como números racionais e irracionais, funções, continuidade etc. e permitiria ao futuro professor discutir de modo mais amplo o conhecimento que irá lecionar (Categoria 2 [dos educadores matemáticos]). (MOREIRA; VIANNA, 2016, p. 533). 
Se considerarmos as categorias apontadas por Shulman (1987) para a formação Matemática do professor de Matemática, quais sejam, (i) o domínio do conteúdo ou conhecimento da matéria que o professor ministra; (ii) o conhecimento curricular sobre os programas e ferramentas de ensino e (iii) o conhecimento pedagógico, considerado como os modos de formular e apresentar os conteúdos aos estudantes (SHULMAN, 1987 apud CALDATTO et al., 2016); a diferença apontada acima e os objetivos elencados pelo Profmat em seu regimento nacional (SBM, 2017), podemos concluir que o programa visa primordialmente atender à primeira categoria em ambos os casos.

Caldatto et al. (2016) apresentam uma análise do currículo do Profmat no contexto de formação de professores de Matemática. Os autores apontam, embasados na literatura e na análise curricular do programa, que este mantém um distanciamento, desarticulação (CALDATTO et al., 2016, p. 918) ou ainda, separação, entre o conhecimento matemático acadêmico e o necessário para a atuação na escola básica presente nas licenciaturas em Matemática, defendendo que este mestrado profissional em Matemática não contempla as outras dimensões apontadas por Shulman (1987), necessárias para a formação docente, além daquela do conhecimento do conteúdo. Os autores apontam uma tricotomia intrínseca "que se expressa pela separação ou pelo desencontro entre o que estuda/aprende nas disciplinas de Matemática, o que estuda/aprende nas disciplinas didático-pedagógicas e o que estuda/aprende na prática escolar" (CALDATTO et al., 2016, p. 924).

A importância para o professor de Matemática das duas últimas instâncias citadas por Shulman não é o foco do Profmat. De fato, não é um dos objetivos do curso aprofundar-se nos conhecimentos curriculares ou didático-pedagógicos. O objetivo do Profmat, explícito em seu regimento, é fornecer conhecimento matemático 'profundo'. Da mesma forma, entendemos que qualquer programa que apenas privilegie o conhecimento das componentes práticas curriculares também não atenderia à formação do professor, se deixasse de lado o conhecimento matemático básico e avançado.

A origem desta concepção ou desenho do Profmat, como curso de formação continuada com ênfase no conhecimento do conteúdo matemático, pode ser traçada em entrevistas do Professor Elon Lages Lima (LIMA, 1989; LIMA, 1995). Em entrevista ao Jornal do Brasil, defendeu que os professores deveriam passar por avaliações contínuas, mesmo depois de efetivados, mencionando que, em outros países, esta prática é comum.

Diante do exposto, a única ação viável deve ser dirigida ao professor, visando melhorar a qualidade do seu trabalho. O problema é bem menor nas escolas particulares, onde é possível manter os bons professores melhorando seus salários e se livrar dos piores demitindo-os. (É possível, mas nem sempre isso é feito.) $\mathrm{Na}$ 
escola pública, que abriga a vasta maioria dos alunos (e que deveria abrigar todos), a situação é mais complicada. Aumentar simplesmente os salários não resolve nada porque a qualidade dos professores que nela trabalham não vai melhorar por isso. Se o problema do professorado consiste em mau preparo e baixos salários, as duas coisas devem ser atacadas simultaneamente. Acho que deveria haver todo ano um exame nacional para habilitação de professores, feito em três níveis: $1^{\mathrm{a}}$ a $4^{\mathrm{a}}$ série, $5^{\mathrm{a}}$ a $8^{\mathrm{a}}$ série e ensino médio. Acho que deveria haver uma tabela salarial especial para professores aprovados nesse exame (LIMA, 1995, p. 5).

Em outra ocasião, em entrevista a Voloch e Martignon, publicada em 1989, na Revista Matemática Universitária, destacamos: “...comecei a dar aulas de Matemática aos 18 anos sem ter terminado o segundo grau. Estava numa cidade desconhecida, sem dinheiro e sem emprego. Dava aulas para sobreviver. [...] adquiri o livro de Cálculo do Courant. [...] Lembro da estranheza que me causou o teorema de Heine-Borel” (LIMA, 1989 - grifos nossos).

Acreditamos que, ainda hoje, a maior parte dos interessados em cursar o mestrado profissional em Matemática tem uma razão importante, alheia ao interesse puro na disciplina, para ingresso no curso: a possibilidade de ascensão na carreira do magistério público, além da bolsa Capes durante o período que fizer jus (este período pode variar de acordo com o desempenho do cursista), ou seja, mantém-se uma coincidência neste ponto: a questão de almejar a própria sobrevivência.

Das concepções iniciais, restou ao Profmat o crivo das avaliações nacionais: inicialmente todas as avaliações nas disciplinas do primeiro ano, e a partir de 2016 apenas o Exame Nacional de Qualificação (ENQ), que é condição necessária para que o aluno possa submeter sua dissertação de mestrado. O ENQ constitui-se, de fato, no maior obstáculo para a conclusão do Profmat, e traduz a essência da mensagem de Lima em entrevista ao Jornal do Brasil. Registre-se que o ENQ é aplicado em cada polo, formulado por uma comissão acadêmica de cunho nacional e corrigido por uma equipe também nacional. Uma das características do ENQ é a necessidade de demonstração dos resultados matemáticos, com várias de suas questões apresentando enunciados como "Mostre que...", "Prove que..." etc.

Constatamos a existência de um estranhamento por grande parte dos professores, cursistas do Profmat, sobre o que seja uma demonstração, mesmo que esta seja prática recorrente nas disciplinas, especialmente as básicas, que são oferecidas logo no primeiro ano, como preparação ao ENQ. Nelas, por exemplo, ensina-se a caracterização de funções afins, de funções exponenciais e de funções logarítmicas. Consideramos uma meta interessante para a formação de professores, que estes, em proporção relevante no sistema de ensino do Brasil, pudessem constatar o que é a essência destas classes de funções, em vez de restringirem os 
problemas em que elas se aplicam àqueles de vestibular ou de concurso. Observe-se que, apesar de análogo, o estranhamento que citamos do Prof. Lima em relação ao Teorema de Heine-Borel é de caráter pessoal ou individual, de um sujeito interessado, enquanto o estranhamento dos professores que participam de um curso ofertado em nível nacional tem uma dimensão social ou cultural.

Breda (2016) apresenta dados interessantes sobre o que significaria a "melhoria no ensino da Matemática”, na concepção dos professores cursistas do Profmat, analisando 29 (vinte e nove) Trabalhos de Conclusão de Curso (TCC) do Rio Grande do Sul. A autora faz uma análise sobre as inovações propostas nos TCC - considerada sob três diferentes aspectos: i) Matemática, na qual se contempla ou a incorporação de conteúdos de nível superior na Educação Básica, ou o estabelecimento de conexões intraMatemáticas ou extraMatemáticas); (ii) inovação em recursos, que se caracteriza pela incorporação de materiais visuais e manipulativos ou pela incorporação de recursos informáticos; (iii) em valores em que se introduz o pensamento crítico e a cidadania. A análise da autora permite concluir que o impacto na prática docente não se efetiva, uma vez que, como já apontado anteriormente, não existe no Profmat quase nenhuma correlação com os aspectos didáticos e pedagógicos, porém, também conclui que os professores cursistas que implementam atividades nas salas de aula de Matemática nas escolas em que atuam, entendem que houve melhoria no ensino, uma vez que

abordam a incorporação de conteúdos matemáticos de nível superior na Educação Básica, entendem tal inovação nos termos de uma mudança do conteúdo matemático, a qual permite novas maneiras de relacionar e abordar conteúdos matemáticos; a realização de processos relevantes (por exemplo, a generalização, modelação de situações extraMatemáticas, estabelecimento de relações intraMatemáticas e significação) e aulas mais atrativas que despertam o interesse dos alunos (BREDA, 2016, p. 297).

Dos referenciais até aqui expostos, acompanhamos a percepção de que a docência é uma atividade complexa que não se restringe a apenas um aspecto epistemológico. Vários são os fatores - dentre os quais os três destacados, quais sejam, conhecimento matemático, conhecimento didático e conhecimento pedagógico - que influem nas práticas do professor e na formação dos professores de Matemática. Defendendo a necessidade de se procurar abordar cada um destes fatores durante o curso do Profmat, a seguir, apontamos como é singular o papel da disciplina de História da Matemática, visando interferir na prática docente. 


\section{Um papel para a História da Matemática na formação do professor de Matemática}

Schubring (2002) ressalta a importância do conhecimento da História da Matemática para a formação do professor de Matemática. Esta importância dá-se de diferentes maneiras e em diferentes ordens como discutiremos a seguir.

Este autor destaca que a noção de multiplicação se constitui em um obstáculo epistemológico que ficou desconhecido ao longo da História da Matemática. O ponto interessante é a sua afirmação inicial de que "a novidade dessa noção consiste no fato de que ela propõe uma relação entre a História e o ensino da Matemática, uma relação não abstrata, mas, pelo contrário, operacional, na organização do processo de aprendizagem" (SCHUBRING, 2002, p. 27).

A noção clássica da concepção de obstáculo epistemológico de Bachelard pode ser entendida como "do antagonismo entre os conhecimentos derivados, por meio dos sensos e os conhecimentos científicos" (SCHUBRING, 2002, p. 28), o que implica que o conhecimento científico exige uma ruptura com o pensamento sensível, o novo conhecimento é obtido após um conflito com o conhecimento já adquirido.

Ocorre uma hierarquização na aquisição de conhecimento, o que vai ao encontro de ideias de Piaget, de desenvolvimento humano, para quem o desenvolvimento dava-se por fases. "Ambas as teorias, de Bachelard e de Piaget, implicam uma visão teleológica: a certeza de poder conseguir o nível mais "maduro", o mais elevado da ciência e, respectivamente, do pensamento humano" (SCHUBRING, 2002, p. 30).

Partindo dessa aproximação, Schubring (2002) faz uma crítica à concepção utilizada por Brousseau no contexto da didática da Matemática. Para o autor, as ideias de Brousseau desvalorizam a potencialidade da História na formação do professor, uma vez que

[...] a História é considerada basicamente como um museu, sem propriamente apresentar problemas e questões ainda não resolvidos. A ideia de Brousseau não valoriza um papel ativo da História, parece estar ligado com o fato de que ele não integra a parte chave da concepção de Bachelard: a noção de ruptura entre conhecimento sensível e conhecimento científico, embora essa noção apresente uma dimensão muito importante, particularmente para pesquisas didáticas (SCHUBRING, 2002, p. 33).

Consideramos que há importância de se estudar como os conceitos matemáticos foram apresentados, discutidos, recebidos e mudados ao longo da História, devendo-se considerar como os povos e as comunidades matemáticas os concebiam, considerando-se as diferentes culturas e os diferentes contextos. 
Exemplificando o modo como o conceito de multiplicação foi estabelecido ao longo dos séculos, desde Euclides (Livro VII), passando por Descartes e Viète, até Lacroix que em seu manual de Aritmética (1808) tratou do assunto, o que Schubring (2002) nos afirma é que a História, relacionada com o ensino da Matemática, "apresenta um metassaber sobre a Matemática, que constitui uma fonte de reflexão importante para o professor" (SCHUBRING, 2002, p. 51).

Cury e Vianna (2001) apresentam uma abordagem sobre a definição do conceito de ângulo, numa perspectiva histórica. Baseiam-se nas Diretrizes Curriculares para os Cursos de Licenciatura em Matemática, as quais apontam entre as competências do futuro professor o desenvolvimento da compreensão, senso crítico e capacidade para analisar novas ideias, permitindo que avaliem propostas pedagógicas existentes em livros didáticos.

Esses autores discutem diversas versões da definição de ângulo, e tecem considerações sobre atributos das definições como clareza e concisão, não possuírem circularidade, não serem negativas quando podem ser afirmativas. Destacam que o uso de determinada definição pode passar por critérios de escolha do professor, como coerência metodológica, possibilidade de facilitar a apropriação de um novo conceito pelo estudante, além da percepção da maturidade do próprio estudante para compreender uma outra apresentação.

Desta forma, a prática do professor engloba autonomia e reflexão. Neste sentido, a História da Matemática pode ser utilizada como ‘elemento de composição'.

Tentamos mostrar como um professor pode recorrer a ela comparando textos de livros didáticos, textos de dicionários e de livros de História da Matemática. Assim como nos referimos às concepções dos professores sobre a Matemática, também existem as concepções das pessoas sobre a História; há os que defendem, por exemplo, que só podemos fazer a História de gente que já morreu ou de fatos ocorridos em um passado distante... Nossa concepção revela, entretanto, que os professores atuando hoje, em sala de aula, podem, mediante o questionamento sistemático daqueles conceitos que ensinam e de suas próprias concepções de Matemática, dar uma contribuição para fazer essa História de hoje, a do tempo em que vivemos (CURY; VIANNA, 2001, p. 35).

D’Ambrósio (2013, p. 8) defende como posição própria a importância de “dar à História da Matemática um enfoque teórico que considera a origem do pensamento matemático como estratégias desenvolvidas por comunidades para sua sobrevivência e transcendência". Baseado nas ideias de Struik, este autor elenca motivos para se ensinar História da Matemática: 
1. para situar a Matemática como uma manifestação cultural, assim como são manifestações culturais a linguagem, os costumes, os valores, as crenças e os hábitos; 2. para mostrar que as manifestações culturais se dão, de modo diversificado, em todos os povos e em todos os tempos; 3 . para mostrar que a Matemática que se estuda nas escolas é uma das muitas formas de Matemática desenvolvidas pela humanidade; 4. para destacar que essa Matemática teve sua origem nos primórdios das civilizações e se organizou nas culturas da Antiguidade; 5. para saber que desde então a Matemática foi incorporada aos sistemas escolares das nações colonizadas, se tornou indispensável em todo o mundo em consequência do desenvolvimento científico, tecnológico e econômico, e avaliar as consequências socioculturais dessa incorporação. (D'AMBRÓSIO, 2013, p. 10).

Assim, tomados estes motivos, o autor defende uma Matemática diversificada, que se apresenta em manifestações culturais e artísticas, que está presente nos trabalhos das pessoas comuns, fora das escolas formais, que pode ser encontrada nas práticas econômicas e industriais.

Para D’Ambrósio (2013, p. 12), a prática da Matemática acontece no dia a dia, nas comunidades mais simples, as quais “[...] respondem a uma estrutura Matemática que obedece a um rigor adequado para essas práticas. Esse rigor não é, necessariamente, o rigor aceito no ambiente acadêmico". O autor argumenta que o que chamamos de Matemática é sempre uma resposta a uma questão ligada à sobrevivência da espécie humana, permitindo ao homem traçar caminhos que buscam a sobrevivência e transcendência.

Acredita D’Ambrósio (2013) que um curso de Matemática que vise à formação de futuros professores de Matemática deve ser encarado como não apenas um curso de História, mas também contemple simultaneamente aspectos de sociologia, filosofia etc.

A intenção de um curso para Licenciatura não é fazer uma cronologia e nem
uma onomástica comentada, mas, com base na historiografia moderna,
indicar e sugerir direções e sinalizar indagações e questionamentos sobre o
que se lê em diversos textos e estudos que estão disponíveis em livros e
artigos. (D’AMBRÓSIO, 2013, p. 17).

A Matemática, sendo criação humana, está ligada ao desenvolvimento da própria humanidade, respondendo aos anseios da época, às necessidades econômicas e sociais de cada temporalidade.

Esta é, em nossa visão, uma maneira possível de se conceber o papel da História da Matemática na formação dos professores, tanto daqueles que já atuam, quanto daqueles que ainda se encontram em formação inicial: correlacionar o momento histórico com a Matemática que está produzida; perceber que a Matemática não está acabada, pronta; perceber 
que a própria História da Matemática que conhecemos hoje pode ser modificada amanhã, diante de um descobrimento novo, ou de uma nova interpretação.

Lopes e Ferreira (2013) apresentam possibilidades do uso da História da Matemática em sala de aula, pensada como metodologia. Segundo os autores, o resgate da História pode tornar as aulas de Matemática mais interessantes e motivadoras, capacitando os estudantes a desenvolverem um olhar crítico e proporcionando reflexões sobre o uso da Matemática e sobre a existência de correlações entre a Matemática e outras áreas de conhecimento.

Para esses autores, é um equívoco o uso da História da Matemática como ilustração, restrita a fatos isolados, nomes populares na Matemática e datas, sem que haja uma contextualização da temporalidade e culturalidade da ocorrência dos fatos tratados. Neste sentido, afirmam: "é importante que o professor ressalte a proposta de valorização de Histórias sociais e culturais da Matemática e de questionamentos da História da Matemática única, de características eurocentristas" (LOPES; FERREIRA, 2013, p. 83).

Desmitificando a presença de culturas hegemônicas enfatizadas nas propostas curriculares e que criam diferenças entre a Matemática do colonizador e a Matemática do colonizado, desvalorizando a produção Matemática de povos menos favorecidos, os autores concluem que o uso da História da Matemática na sala de aula pode "se tornar um caminho para que o professor apresente, mesmo que maneira subentendida, a cultura Matemática de diferentes povos" (LOPES; FERREIRA, 2013, p. 84).

A História da Matemática pode se tornar um caminho para humanizar a Matemática, aproximando-a da realidade e colaborando para a percepção de que muitas das descobertas Matemáticas tiveram origem em problemas práticos cotidianos que exigiam solução, a "Matemática como parte integral de uma herança cultural diversificada" (LOPES; FERREIRA, 2013, p. 87).

Acreditamos numa História da Matemática que pode contribuir na formação do professor de Matemática, para além daquela muitas vezes elencada nos livros didáticos que apenas citam nomes de matemáticos famosos, lugares imponentes e datas, sem contextualização alguma dos modos de viver e conceber a Matemática dos povos.

Tal contribuição fundamenta-se em que o uso de tópicos de História da Matemática na sala de aula constitui-se numa oportunidade de revisitação ao passado, possibilitando o aprendizado contextualizado com fatos históricos concomitantes, em outras áreas, com a consequente percepção do desenvolvimento da Matemática em seu caráter de criação humana, temporal, espacial e em dependência com as ideologias vigentes à época. Pode ser uma 
oportunidade para a discussão de aspectos críticos à matemática e de como seu ensino e aprendizagem ocorreram e ainda ocorrem.

\section{Um papel para as demonstrações na formação do professor de Matemática}

Morais Filho (2007), respondendo à pergunta “O que é uma demonstração?” afirma que

Dentro de um modelo axiomático, dadas duas proposições $\mathrm{H}$ e $\mathrm{T}$, uma demonstração de que a proposição $\mathrm{H}$ acarreta a proposição $\mathrm{T}$ é uma sequência finita de sentenças $P_{1_{2}} P_{2}, P_{3}, \ldots, P_{k}$, tais que cada uma delas é, ou um axioma, ou uma definição, ou uma hipótese, ou uma sentença resultante de sentenças anteriores, que foi deduzida por argumentações válidas. A proposição final ${ }^{P_{k}}$ da sequência é a proposição T (tese), resultado de todo o processo dedutivo (MORAIS FILHO, 2007, p. 98 - grifo do autor)

O primeiro exemplo deste método de dedução parece ser encontrado na obra 'Elementos', compilada por Euclides (300 a.C.), fato que permite afirmar que a prova há muito tempo vem sendo considerada, e até hoje é, importante na Matemática e nos currículos de Matemática, desde o ensino fundamental até o superior. Como afirma Hanna (2000, p. 5), “[a] prova está viva e saudável na prática Matemática, e continua a merecer um lugar de destaque no currículo de Matemática”.

Este objeto nomeado "demonstração", com o qual o matemático tão bem lida, pode ser encarado como a resposta a um "por quê?" (HANNA; JAHNKE, 2002, p. 44) sobre um enunciado matemático. Essa resposta a um 'por quê' funda-se na perspectiva da busca pela 'verdade' e essa 'verdade Matemática' é encarada muitas vezes na fundamentação das proposições em um sistema axiomático-dedutivo, como acima descrito por Morais Filho.

As correlações entre demonstrações ou prova rigorosa em Matemática e formação de professores já foram discutidas por outros autores. Garnica (1995) fez um levantamento sobre os estudos da demonstração em Matemática, visando à relação "prova rigorosa e formação de professores". O estudo passa pelas esferas da História, Epistemologia e Filosofia, tratando de múltiplos aspectos desde currículo, sala de aula como fonte de pesquisa, historicidade do conceito de prova e tipos de provas que foram aceitas em determinadas épocas e situações, até a abordagem rápida sobre a questão da validação de provas por computadores.

No trabalho deste autor encontramos uma visão sobre 'prova rigorosa' da qual compartilhamos: "[...] a prova rigorosa é tomada como elemento formador do discurso matemático, manifestado em salas de aula - mais claramente aquelas do terceiro grau - pela 
chamada metodologia tradicional vigente, alimentando-se e sendo por ela alimentado" (GARNICA, 1995, p. 14).

Para Garnica, o significado da prova rigorosa na formação do professor de Matemática se faz através de duas concepções distintas, uma de 'natureza técnica' e outra de 'natureza crítica'. A leitura técnica privilegia o uso da demonstração apenas pelo viés sintático, com a função exclusivista de validar o conhecimento matemático por ela gerado; é subjugada por normatizações, procedimentos bem definidos e transmissíveis, objetivando a produção de resultados considerados úteis. A leitura crítica, embora não se desfaça do viés técnico, atenta para os relativismos pertinentes à prova rigorosa e sua dependência com o regime de 'verdade' adotado; preocupa-se com o exame de um fato ou princípio, para produzir um juízo de apreciação. Implica, pois, em uma reflexão intrínseca à elaboração da demonstração, feita por aquele que a lê.

Hanna (1990) defende a existência de três aspectos sob os quais a prova pode ser considerada: a prova formal, a prova 'aceitável' e o ato de 'ensinar' através da prova.

A prova aceitável é aquela vista como um princípio normativo; mais do que enraizada em critérios lógicos, a prova precisa ser compatível com o corpo do conhecimento matemático que define o que é aceitável ao matemático. A prova é considerada um processo social, sendo uma de suas funções ‘promover o entendimento' (HANNA, 1990, p. 7).

Os critérios que os matemáticos parecem aplicar, consciente ou
inconscientemente, são de que uma prova deve vir de premissas específicas e
aceitas, deve apresentar um argumento que não tem falha, e deve levar a um
resultado que, ainda que inesperado, pareça após nova reflexão fazer sentido
no contexto dado pelo conhecimento matemático estabelecido (HANNA,
1990, p. 8).

Sob este viés, o valor da prova está em fazer aparecer relações matemáticas, e não apenas mostrar a validade de um argumento. Para Hanna, ao considerar a prova um meio de comunicação de ideias matemáticas que envolvem um processo social, presente na aceitação de um novo resultado matemático, os educadores conferem ao conceito de prova o caráter de um 'argumento convincente'. A autora defende que uma prova precisa ser simultaneamente válida - no sentido de demonstrar o resultado matemático dentro dos padrões de rigor necessários - e também explicativa - no sentido de explicar porque determinado resultado é válido.

$\mathrm{O}$ ato de se ensinar através de uma demonstração deve incluir a possibilidade de se fazer da própria demonstração a resposta de como o resultado foi possível de ser provado e não apenas de demonstrar o resultado. 
A 'prova formal' é a prova vista sob o viés da conceitualização teórica, na lógica formal, uma sequência finita de afirmações, cada afirmação sendo ela própria um axioma ou advindo de uma afirmação prévia - e, portanto, talvez de um axioma - como resultado de aplicações corretas das regras de inferência, a última sentença sendo o resultado a ser provado, por exemplo, como refletida na definição de Morais Filho (2007) apresentada acima.

Um representante desta corrente formalista é o grupo Bourbaki, pseudônimo de diversos matemáticos franceses, que advoga a Matemática e a prova 'rigorosa' como alternativa única para diversos cursos de Matemática. Segundo Hanna, esta influência pode ser encontrada em educadores que prepararam o currículo do movimento de 'Matemática moderna', para escolas secundárias.

Mais recentemente, Carvalho e Savioli (2013), analisando o papel das demonstrações Matemáticas na Educação Matemática, trazem reflexões acerca das correlações entre demonstrações matemáticas e esta questão da 'verdade' que a demonstração estabeleceria. Utilizando-se de Foucault como referencial teórico, as autoras argumentam que não existe $a$ verdade e sim, uma verdade que é instituída, combinada, obtida.

[...] em Matemática, ao falarmos de verdade devemos falar em prova ou demonstração, aquilo que, dentro de um conjunto pré-estabelecido de axiomas ou premissas assumidas como verdadeiras e fundamentado em sequências lógicas ou regras de inferência, atesta a veracidade de uma afirmação. [...] A verdade é combinada. Fixam-se as regras fixando-se o modelo axiomático, aquilo de que se parte, o incontestável. O único desafio neste contexto é justamente não se esquivar dele (CARVALHO; SAVIOLI, 2013, p. 50).

A questão a ser considerada neste contexto é a de que, sendo a verdade estabelecida pela demonstração uma das verdades, combinada culturalmente, está ela, sujeita a outros fatores que não apenas restrita aos modelos axiomáticos defendidos pela Matemática mais 'pura'? As demonstrações em Matemática estão, explícita ou implicitamente, em dependência direta de outros fatores como os sujeitos que as realizam (CARVALHO, 2004) ou, como defendemos neste artigo, dependem da temporalidade, do tempo histórico cultural no qual foram elaboradas.

Estas dependências, uma vez apreendidas pelos professores, podem trazer contribuições para a sala de aula de Matemática, na perspectiva didático-pedagógica. 


\section{Acerca da Metodologia}

Esta pesquisa tem caráter predominantemente qualitativo, de natureza investigativa. Para alcançar os objetivos propostos neste artigo, lançamos mão do paradigma qualitativo (CHIZZOTTI, 2006; REY, 2015; GARNICA, 2001) e de pressupostos teórico-metodológicos oriundos dos campos de conhecimento e de práticas da Educação Matemática. Para a coleta de dados, valemo-nos da aplicação, em dois momentos distintos, de duas atividades com vários itens, com problemas contextualizados dentro da História da Matemática e que versavam sobre demonstrações em Matemática. Estas atividades são expostas a seguir.

Para Chizzotti (2006), atualmente a abordagem qualitativa de pesquisa envolve as ciências humanas e sociais, sendo transdisciplinar, assumindo variados paradigmas de análise oriundos de diferentes correntes do pensamento filosófico e linhas teóricas como "o positivismo, a fenomenologia, a hermenêutica, o marxismo, da teoria crítica e do construtivismo" (2006, p. 221).

Consequentemente, a pesquisa qualitativa assume como uma de suas premissas o caráter construtivo do conhecimento humano, sendo este passível de interpretação, sujeito às próprias práticas e concepções do sujeito pesquisador. Sendo influenciada por aquele que realiza a pesquisa, tal abordagem não é estática, torna-se passível de re-significações. Como aponta Rey $(2015$, p. 7),

(...) não existe nada que possa garantir, de forma imediata no processo de pesquisa, se nossas construções atuais são as mais adequadas para dar conta do problema que estamos estudando. A única tranquilidade que o pesquisador pode ter nesse sentido se refere ao fato de suas construções the permitirem novas construções e novas articulações entre elas, capazes de aumentar a sensibilidade do modelo teórico em desenvolvimento para avançar na criação de novos momentos de inteligibilidade sobre o estudado, ou seja, para avançar na criação de novas zonas de sentido.

A pesquisa qualitativa delega aos sujeitos envolvidos papel ativo, incorpora-os à própria prática de investigação, responsabilizando-os em relação à sua pesquisa, num dinamismo intrínseco ao ato de pesquisar: "não há modelos fixos, não há normatização

absoluta. (...) É investigação que interage e, interagindo, altera-se. É alteração que se aprofunda nas malhas do fazer e do formar-se em ação" (GARNICA, 2001, p. 42).

Nesta modalidade de pesquisa, pesquisador e pesquisados, sujeitos nos quais circulam diferentes tipos de ideias, associações múltiplas, processos simbólicos e emoções são elementos essenciais. Para Rey (2015, p. 24), “a subjetividade está constituída tanto no sujeito 
individual, como nos diferentes espaços sociais em que se vive, sendo ambos constituintes da subjetividade". Assim, o sujeito movimenta-se e ao movimentar-se, circulando nos diferentes espaços sociais, atualiza sua condição de sujeito, a partir das tensões e sentidos produzidos em seu trânsito pelas diversas atividades.

Uma vez delineado o tipo de pesquisa, a fase de coleta de dados torna-se crucial para o encaminhamento da mesma.

Para Rey (2015, p. 61),

[o] uso de instrumentos como vias de produção de sentido subjetivo concede a maior importância aos aspectos subjetivos que caracterizam a relação do sujeito com o instrumento, bem como os processos envolvidos na produção de sentido subjetivo ante o instrumento.

Finalmente, nas análises dos dados que levaram à obtenção dos resultados, espera-se obter avanços em determinadas técnicas e/ou teorias, dentro de uma área.

\section{Sujeitos e procedimentos}

Participaram desta pesquisa 10 professores de Matemática do Profmat, que aqui serão identificados por P1, P2, ..., P10. Todos tiveram contato com a disciplina História da Matemática (Eletiva I), ofertada no primeiro período do segundo ano de curso, e todos já cursaram as disciplinas básicas: Aritmética, Geometria, Números e Funções Reais, Matemática Discreta, além de um curso de Resolução de Problemas realizado no final do primeiro ano ${ }^{1}$. A experiência dos professores em lecionar Matemática é variada, mas a maioria possui mais de 9 (nove) anos de magistério na Educação Básica. Todos foram devidamente informados sobre a natureza da pesquisa e assinaram um Termo de Consentimento Livre e Esclarecido (TCLE) sobre a mesma.

Para a coleta de dados desta investigação, foi utilizado como instrumento uma atividade concebida para avaliar a compreensão, pelos professores, do conceito de demonstração. Esta atividade consistiu na resolução de três questões: a primeira sobre os números figurados (como tratados pelos Pitagóricos) composta por três itens; a segunda sobre indução Matemática e a terceira sobre a irracionalidade de um número, estas últimas compostas por dois itens cada. O tempo disponível para a aplicação desta atividade foi de três horas. Cada participante respondeu, individualmente, às três questões propostas. Neste artigo,

\footnotetext{
A matriz curricular nacional pode ser encontrada em

http://www.profmatsbm.org.br/funcionamento/matriz. Acesso em 29/05/2017.
} 
devido ao espaço, vamos apresentar nossas análises para as repostas fornecidas por seis dos participantes para os itens (b) e (c) da primeira questão.

\section{Descrição da Atividade}

A atividade foi introduzida com uma exposição dialogada, a qual relatamos brevemente em seguida, além de algumas generalidades do pensamento grego durante o século V A.C. e o surgimento da polis. Foram propostos três itens, adiante expostos, acompanhados de um pequeno fragmento retirado de Baron $(1985$, p. 17) no qual constam as expressões algébricas atuais e as figurativas que representam os números quadrados e retangulares que acompanhavam as questões. $\mathrm{O}$ item (b) desta atividade é um exercício proposto por Roque e Carvalho (2012, p. 79).

Discutimos, seguindo Baron (1985), que a escola fundada por Pitágoras (c. 500 A.C.) possuía um caráter misto, haja vista que suas atividades englobavam "ritos religiosos, cerimônias de iniciação e rituais de purificação; uma ordem estritamente monástica parece ter sido ditada prescrevendo inclusive o vegetarianismo e o poder comum sobre as coisas" (BARON, 1985, p. 15). E, fazendo uso do livro referência da disciplina de História da Matemática, Roque e Carvalho (2012), também observamos que o conhecimento atual de que dispomos da Matemática grega é indireto, oriundo de fontes como os escritos de Platão e Aristóteles, além de Pappus e Proclus. Segundo estes autores, no século V A.C., "o pensamento geométrico e técnico já estava desenvolvido, mas não temos como saber se os pitagóricos contribuíram para isso" (ROQUE; CARVALHO, 2012, p. 63).

Ainda contextualizando historicamente a atividade, e de acordo com Roque e Carvalho (2012), enfatizamos que a escola pitagórica se baseava em uma teoria de números 'concreta', os números figurados, para oferecermos uma explicação desse conceito e sua importância. "Os números figurados dos pitagóricos consistiam em uma multiplicidade de pontos que também não eram pontos matemáticos, mas remetiam a elementos discretos: pedrinhas em uma certa configuração" (ROQUE; CARVALHO, 2012, p. 66). Segundo Baron (1985, p. 16), "o conceito de número figurado gerou muitos frutos e [..] teve influência até o século XVII. Na realidade, a "figura" como um numeral teve origem na escola de Pitágoras".

Para Miorim (1998), é incontestável a importância da influência de Pitágoras e dos pensamentos advindos de sua escola para a Matemática e seu ensino. "Revestida de grande misticismo, acreditando que a purificação só poderia ser alcançada através do conhecimento puro, essa escola seria responsável não apenas pelo estudo de novos resultados a respeito dos 
números e da geometria, mas, especialmente, pelo "estabelecimento da Matemática como uma disciplina racional” (MIORIM, 1998, p. 15). Todavia, esta autora faz um alerta: "a escola pitagórica também foi responsável pela introdução da concepção, existente até hoje, de que os homens que trabalham com os conceitos matemáticos são superiores aos demais" (MIORIM, 1998, p. 15).

Em linguagem atual, podemos dizer que os números pentagonais, que denotaremos por $P_{n}$, são números naturais que contam os pontos num conjunto de pentágonos aninhados tal que o maior pentágono possui ${ }^{n}$ pontos, em cada um de seus lados. Os números quadrados, $Q_{n}$, são números naturais que contam os pontos num conjunto de quadrados aninhados tal que o maior quadrado possui ${ }^{n}$ pontos, em cada um de seus lados. Os números triangulares, ${ }^{T_{n}}$, são números naturais que contam os pontos num conjunto de triângulos aninhados tal que o maior triângulo possui ${ }^{n}$ pontos, em cada um de seus lados.

O enunciado completo da primeira questão da atividade é o seguinte:

As demonstrações feitas pelos pitagóricos parecem ter se baseado na evidência visual fornecida pelos números figurados.

(a) Desenhe os quatro primeiros números triangulares, quadrados e pentagonais, respectivamente.

(b) Sejam $T_{n}, Q_{n} e^{P_{n}}$, respectivamente, os números triangulares, quadrados $e$ pentagonais de ordem $n$. Mostre, sem utilizar aritmética ou álgebra, simplesmente reorganizando diagramas de números figurados, que $P_{n}=Q_{n}+T_{n-1}$.

(c) Sua resposta ao item (b) é uma demonstração em Matemática? Por quê?

Apresentamos aqui seis respostas obtidas para os itens (b) e (c), as respostas dos outros quatro participantes são muito parecidas com as analisadas aqui.

Figura 1 - Resposta P1

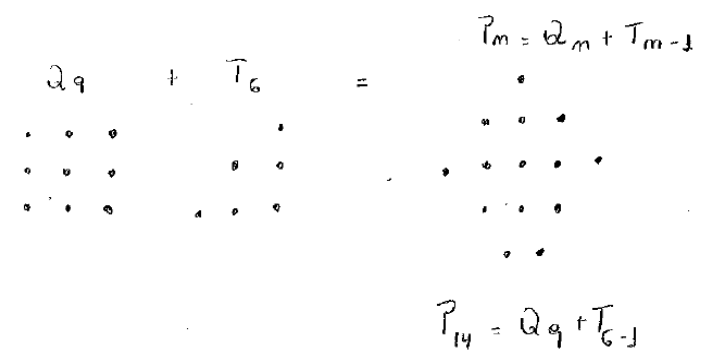


c) Sua resposta ao item (b) é uma demonstração em Matemática? Por quê?

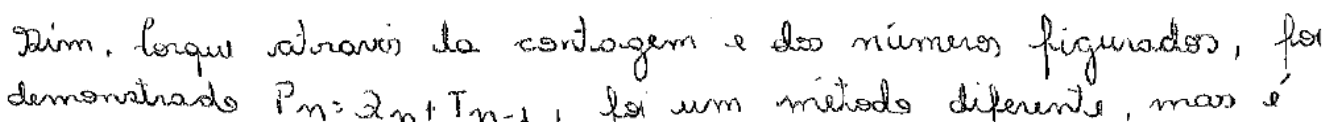
uma demonstracasos matemótuca.

Fonte: Autores

\section{Figura 2 - Resposta P2}

$$
\begin{aligned}
& P=Q_{1}+t_{1-1} \quad P_{1}=\text {. } \\
& \}_{2} \quad 0,+1 \\
& j,, 0, i^{4},
\end{aligned}
$$

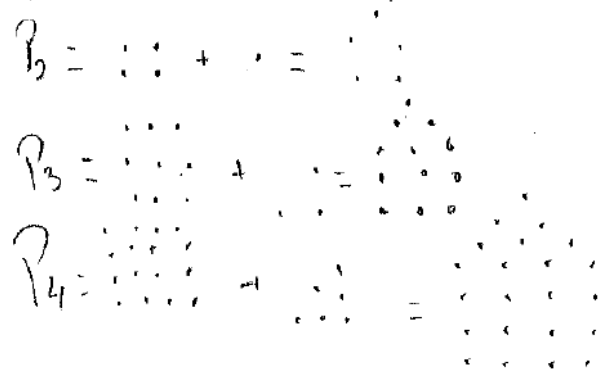

c) Sua resposta ao item (b) é uma demonstração em Matemática? Por quê?

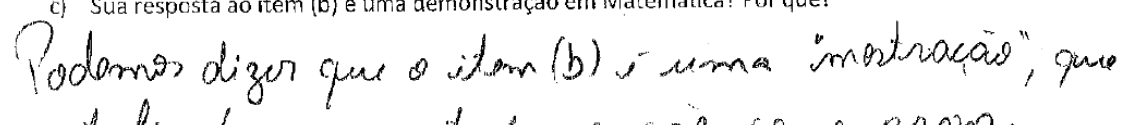

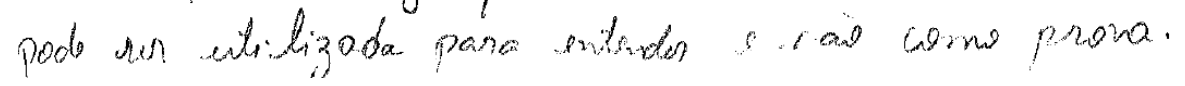

Fonte: Autores

Figura 3 - Resposta P3

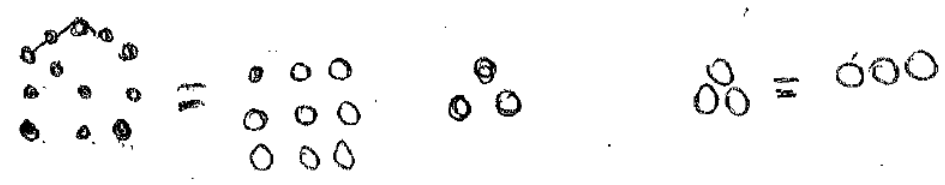

$$
\begin{aligned}
& \begin{array}{l}
00 \\
00 \\
000 \\
000
\end{array}=\left[\begin{array}{ll}
000 \\
000 & 000 \\
000 & 0
\end{array}\right]+\begin{array}{l}
000 \\
000 \\
000 \\
000
\end{array}
\end{aligned}
$$

c) Sua resposta ao itẹn (b) é uma demonstração em Matemática? Por quê?

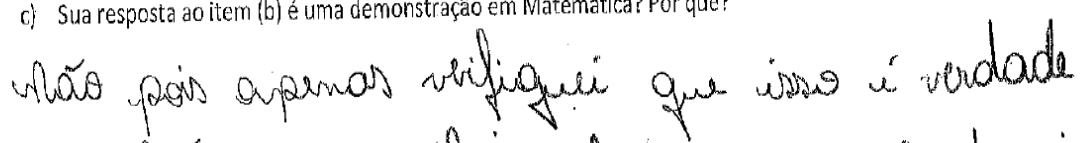

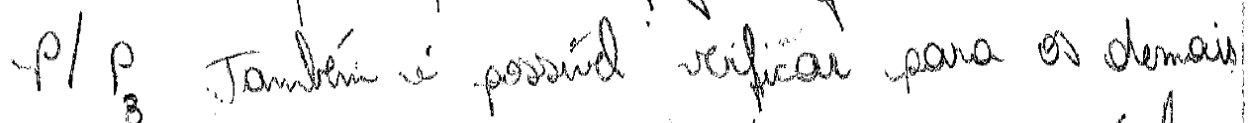

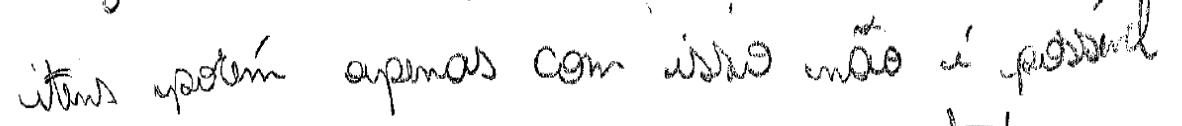

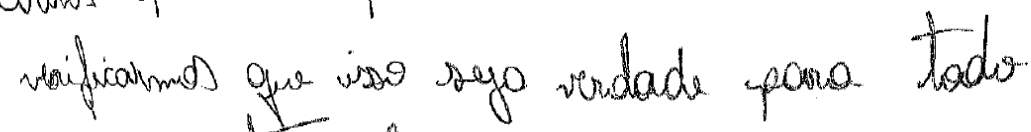
mímore pomageral

Fonte: Autores 


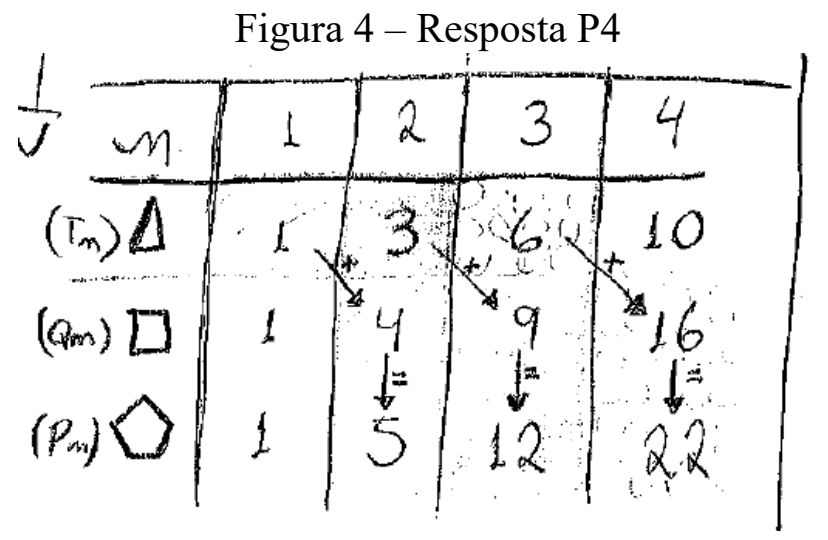

c) Sua resposta ao item (b) é uma demonstração em Matemática? Por quê?

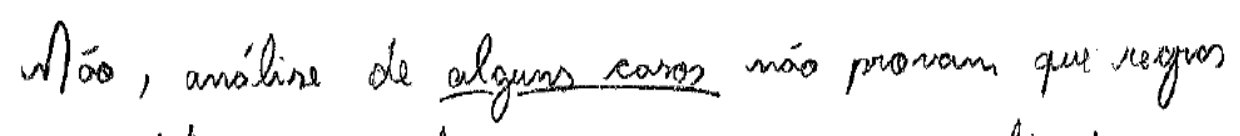

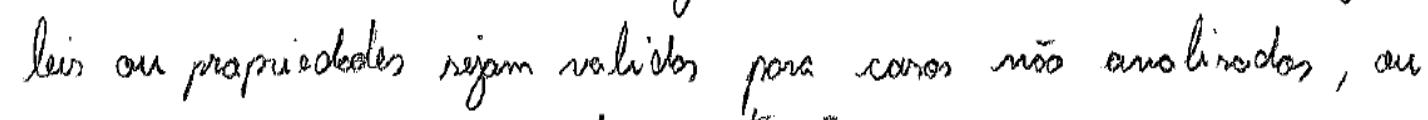

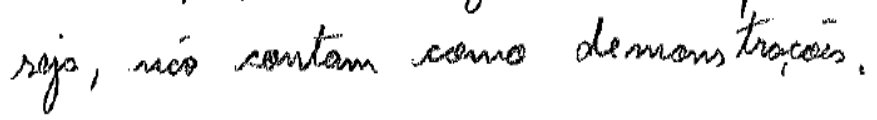

Fonte: Autores

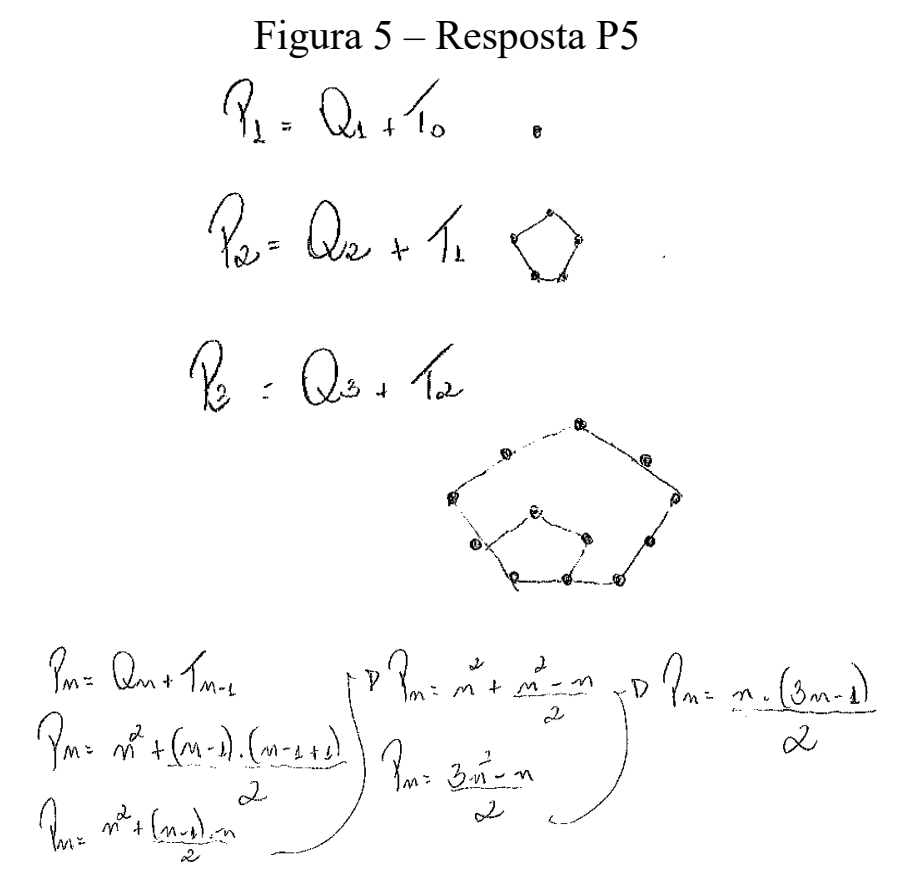

c) Sua resposta ao item (b) é uma demonstração em Matemática? Por quê?

Acrevito guesim por tratarndes de um concoito geomántico e contagricm para PRovar o Que se Pere.

Fonte: Autores 
Figura 6 - Resposta 6
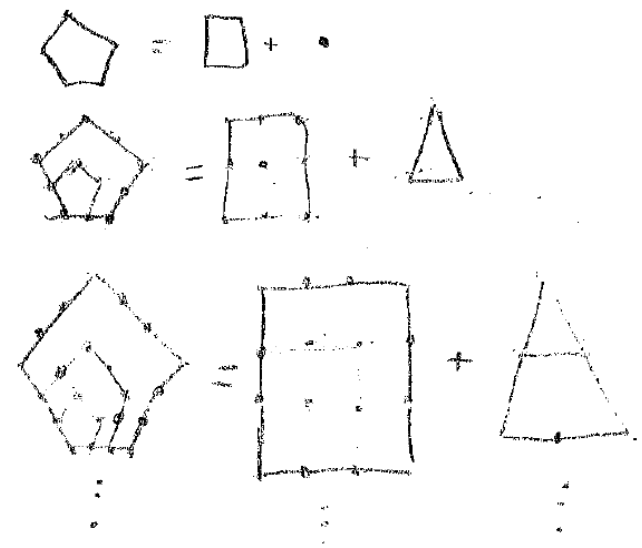

c) Sua resposta ao item (b) é uma demonstração em Matemática? Por quê?

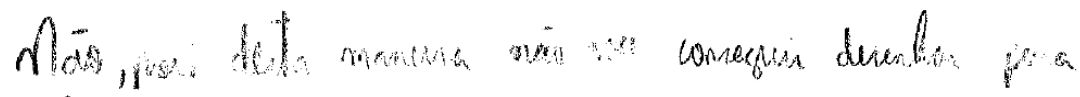

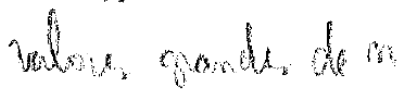

Fonte: Autores

\section{Discussão dos dados coletados}

As respostas obtidas apresentam diferentes concepções do que é uma demonstração em Matemática.

Entre os dez participantes, dois responderam que 'sim', que o resultado obtido por meio de um desenho/figura era suficiente para obter a demonstração do fato, os professores P1 e P5. Ambos os professores se utilizam da palavra 'contagem' para justificar a resposta afirmativa para o item (c). Entretanto, P5 acrescenta um conjunto de expressões algébricas, numa tentativa de generalização do problema e apelo à álgebra, deixando de seguir a orientação do enunciado da atividade.

Um dos participantes, P2, utiliza a palavra 'mostração', mas acrescenta que "não é prova", logo acredita que não demonstrou o fato proposto. Relembrando Hanna (1990), este termo remete a provas que explicam.

Os participantes $\mathrm{P} 3, \mathrm{P} 4, \mathrm{P} 7, \mathrm{P} 8, \mathrm{P} 9$ e $\mathrm{P} 10$ ofereceram uma resposta negativa para se o item (b) teria demonstrado o resultado. As diferentes justificativas abarcam a ideia de que “comprovar para alguns valores de ${ }^{n}$, mas não para todos", não é suficiente. O participante P3, Figura 3 acima, responde 'não' e justifica que verificou apenas para o número pentagonal de ordem 3. A seguir acrescenta "também é possível verificar para os demais itens, porém apenas com isso não é possível verificarmos que isso seja verdade para todo número pentagonal". Entendemos que esta resposta se aproxima da justificativa citada por P4, 
também exposta acima. Assim, sessenta por cento do universo de respostas apresentou que, em se tratando de números naturais, não é suficiente para obter um resultado para um certo número e inferir que o resultado está correto para todo natural $n$. Um dos professores, P6 acima, responde 'não, e apresenta um argumento geométrico: "Não, pois desta maneira não vou conseguir desenhar para valores grandes de $n$ "; sem considerar álgebra ou aritmética.

Em relação ao instrumento de investigação, é oportuno mencionar o trabalho de Biza et al. (2009), por trazer evidência que coincide com nossa conclusão, no sentido de que uma argumentação visual não é vista, por grande parte dos professores, como suficiente para uma demonstração, ainda que possa ser reconhecido como suficiente para um contra-exemplo (o referido trabalho foi conduzido com professores do ensino básico da Grécia e Inglaterra).

A análise das respostas a estas questões depende, de partida, de seu próprio enunciado. Chama a atenção a palavra simplesmente no item b, como a antecipar que o argumento usando figuras já não seria realmente uma demonstração. A relação a ser verificada é também escrita de forma algébrica, em linguagem atual. Uma possibilidade de resposta esperada seria a seguinte:

As figuras são aninhadas. Ao acrescentar uma unidade a mais na medida de um lado de um triângulo, acrescentamos um lado com ${ }^{n}$ pontos. Ao acrescentar uma unidade a mais na medida de um lado de um quadrado, acrescentamos dois lados com ${ }^{n}$ pontos, um destes comum. Ao acrescentar uma unidade a mais na medida de um lado de um pentágono, acrescentamos três lados com ${ }^{n}$ pontos, dois destes comuns. Assim, se no nível $k$, vale a propriedade indicada algebricamente por $P_{k}=Q_{k}+T_{k-1}$, no próximo nível temos que verificar que adicionamos a mesma quantidade de pontos em ambos os membros, o que é verdadeiro pois

$$
3(k+1)-2=(2(k+1)-1)+k .
$$

Esta resposta não deixa de usar a linguagem algébrica, pois seria necessário fazer desenhos com reticências misturadas aos pontos das figuras para se ater completamente ao enunciado. Entretanto, o nível de uso da linguagem algébrica aqui é intermediário (sincopado). Cabe destacar ainda o uso do princípio de indução finita na argumentação. Por fim, mencione-se o esforço, do ponto de vista de linguagem, para a produção desta resposta.

A questão proposta traz a perspectiva histórica sobre o que se entende como demonstração. Ao solicitar que se evite a linguagem algébrica, dificulta a análise para o matemático com formação atual de tal modo que, como se viu, a maioria não se sinta convencida de que apresentou realmente uma demonstração. 
Lembrando Morais Filho (2007) sobre o que é hoje uma demonstração em Matemática, como expusemos anteriormente, a resposta ao item (b) seria 'não'. A utilização do Princípio de Indução Finita é, de modo subliminar, invocada por algumas das respostas (ver P3 e P4). Aqui devemos apontar uma hipótese a respeito da atitude destes alunos ao não tornar explícita a menção do princípio de indução (P.I). Todos os participantes o conhecem, pois faz parte da ementa da disciplina obrigatória de Matemática Discreta, oferecida no primeiro período do Profmat e também considerando a segunda questão (não analisada aqui) que solicitava explicitamente a utilização deste princípio para provar uma certa expressão numérica. $\mathrm{O}$ fato de o enunciado indicar que não se deveria utilizar aritmética ou álgebra para a resolução pode ter induzido os professores a não utilizar o P.I.. Em alguma medida, o estudante interpretaria as questões no contexto da disciplina (no caso História da Matemática) e poderia ter concluído que não era mesmo para se fazer uma demonstração (independentemente da historicidade mencionada para o sentido que esta deva ter): este aspecto é conjuntural. Responderam de acordo com o contexto no qual se encontravam.

Alternativamente, vislumbramos que a realização da atividade e as respostas obtidas neste conjunto de participantes fornecem indícios de que, mesmo após cursar as disciplinas consideradas básicas do Profmat, ofertadas com a utilização dos materiais propostos pelo IMPA/SBM, que estão repletos de teoremas e exemplos que exigem demonstrações de fatos matemáticos, o objeto 'demonstração' e os modos de executá-lo persistem como fonte de dúvidas nos professores. Este aspecto é estrutural, a dificuldade diante de apresentar uma demonstração de um fato matemático pode permanecer, independente de treinamento e da grade curricular do programa.

Neste contexto apresentado, as considerações de Hanna (1990, 2000), de Hanna e Jahnke (2002) e de Garnica (1995), as quais foram discutidas anteriormente, são ainda mais significativas e importantes, uma vez que, se estamos convencidos da necessidade de diversas competências e habilidades necessárias para o professor da Educação Básica tais como apontadas por Shulman (1987), temos que o conhecimento formal de Matemática é uma delas, embora não seja o único. Consideramos que as colocações destes autores se mantêm pertinentes e atuais.

\section{Conclusão}

Com relação ao uso da História da Matemática na sala de aula, no caso, na sala de aula de um curso de pós-graduação, o Profmat, parece-nos que se constitui de fato num ambiente 
propício para ensejar discussões de Matemática, inclusive de níveis mais elaborados e formais, como foi o caso que contemplamos, com a discussão do objeto demonstrações'.

A síntese que emerge das atividades descritas tem duas alternativas de interpretação, não excludentes. A primeira, conjuntural: o estudante cursista deste programa encara uma atividade da disciplina de História da Matemática como descolada do formalismo matemático, sem que isto esteja explicitamente afirmado na proposta, por concepções prévias a respeito da disciplina. A segunda, estrutural: apesar de estarem expostos a argumentos formais ao longo de várias outras disciplinas do programa do Profmat, a prática da demonstração é ainda incipiente, ainda que muitos sejam capazes de perceber o que não é uma demonstração.

Defendemos o uso de uma História da Matemática na sala de aula que não seja apenas rememoração de datas e fatos históricos do passado, mas que seja uma oportunidade de revisitação ao passado, uma possibilidade de aprender com os fatos históricos e perceber o desenvolvimento da Matemática em seu caráter de criação humana, temporal, espacial e em dependência com as ideologias vigentes à época.

De todo modo, a formulação de novas atividades, que tragam mais patentemente o caráter histórico do conceito de demonstração, delineia-se como um projeto futuro, desnudando a potencialidade natural da disciplina de História da Matemática, como espaço para caracterizar a Matemática como ciência construída pela e para a atividade humana.

\section{Referências}

BARON, Margareth E. Curso de História da Matemática: origens e desenvolvimento do Cálculo. Unidade 1: A Matemática grega. Tradução de José R. B. Coelho; Rudolf Maier e Maria José M. M. Mendes. Brasília: Universidade de Brasília, 1985.

BIZA, I.; NARDI, E.; ZACHARIADES, T. Do images disprove but do not prove? Teachers' beliefs about visualization. Proceedings of the ICMI Study 19 conference: Proof and Proving in Mathematics Education, vol. 1, Taiwan, 2009.

BREDA, Adriana. Melhorias no ensino de Matemática na concepção de professores que realizam o mestrado Profmat no Rio Grande do Sul: uma análise dos trabalhos de conclusão de curso. 2016. Tese (Doutorado em Educação em Ciências e Matemática) - PUC, Porto Alegre, 2016.

CALDATTO, Marlova E.; PAVANELLO, Regina M.; FIORENTINI, Dario. O PROFMAT e a formação do professor de Matemática: uma análise curricular a partir de uma perspectiva processual e descentralizadora. Boletim de Educação Matemática (BOLEMA). Rio Claro, v. 30, n. 56, p. 906 - 925, dez. 2016. 
CARVALHO, Ana M. F. T. A extimidade da demonstração. 2004. Tese (Doutorado em Educação Matemática) - IGCE, UNESP, Rio Claro (SP), 2004.

CARVALHO, Ana M. F. T.; SAVIOLI, Ângela M. P. D. Demonstrações em Matemática na Educação Matemática no Ensino Superior. In: FROTA, Maria Clara R.; CARVALHO, Ana Márcia F. T. de; BIANCHINI, Bárbara L. (Orgs.). Marcas da Educação Matemática no Ensino Superior. Campinas, SP: Papirus, 2013.

CHIZZOTTI, Antonio. A pesquisa qualitativa e seus fundamentos filosóficos. In:

CHIZZOTTI, A. Pesquisa em ciências humanas e sociais. Petrópolis, RJ: Vozes, 2006, p. 33-61.

CURY, Helena N.; VIANNA, Carlos R. Ângulos: uma "História" escolar. Revista História \& Educação Matemática. v. 1, n. 1, pp. 23-37, jan. / jun. 2001.

D'AMBRÓSIO, Ubiratan. Por que e como ensinar História da Matemática. Revista de Matemática, Ensino e Cultura (REMATEC). Natal, ano 8, n. 12, p. 07-21, Jan.-Jun 2013.

GARNICA, Antonio V. M. Fascínio da técnica, declínio da crítica: Um estudo sobre a prova rigorosa na formação do professor de Matemática. 1995. Tese (Doutorado em Educação Matemática) - IGCE, UNESP, Rio Claro (SP), 1995.

GARNICA, Antonio V. M. Pesquisa qualitativa e Educação (Matemática): de regulações, regulamentos, tempos e depoimentos. Mimesis, Bauru, v. 22, n. 1, p-35-48, 2001.

HANNA, Gila. Some pedagogical aspects of proof. Interchange. 21(1): 6-13, 1990.

HANNA, Gila. Proof, explanation and exploration: an overview. Educational Studies in Mathematics, n. 44, p. 5-23, 2000.

HANNA, Gila; JAHNKE, Helen N. Arguments from physics in mathematical proofs: an educational perspective. For the Learning of Mathematics. v. 22, n. 3, p. 38-45, 2002.

HOUAISS, Antônio; VILLAR, Mauro S. Dicionário Houaiss da Língua Portuguesa. Rio de Janeiro: Objetiva, 2001.

LIMA, Elon L. Elon Lages Lima comenta sua Vocação de Matemático e Divulgador da Matemática. Entrevista concedida a J. F. Voloch e L. Martignon. Revista Matemática Universitária, Rio de Janeiro, n. 9/10, 1989.

LIMA, Elon L. Sobre o ensino de Matemática. Entrevista concedida ao Jornal do Brasil. Revista do Professor de Matemática, Rio de Janeiro, v. 26, pp. 1-5, 1995.

LOPES, Lidiane S.; FERREIRA, André Luis A. Um olhar sobre a História nas aulas de Matemática. Abakós. Belo Horizonte, v. 2, n. 1, p. 75 - 88, 2013. 
MIORIM, Maria A. Introdução à História da Educação Matemática. São Paulo: Atual, 1998.

MORAIS FILHO, Daniel C. Um convite à Matemática: fundamentos lógicos, com técnicas de demonstração, notas históricas e curiosidades. 2. ed. (revista e ampliada). Campina Grande: EDUFCG, 2007.

MOREIRA, Plínio C.; CURY, Helena N.; VIANNA, Carlos R. Por que análise real na Licenciatura? Zetetiké, Campinas, SP, v. 13, n. 23, p. 11-42, jan./jun. 2005.

MOREIRA, Plínio C.; VIANNA, Carlos R. Por Que Análise Real na Licenciatura? Um Paralelo entre as Visões de Educadores Matemáticos e de Matemáticos. Boletim de Educação Matemática (BOLEMA). Rio Claro, v. 30, n. 55, p. 515 - 534, ago. 2016.

REY, Fernando González. Pesquisa Qualitativa e Subjetividade. Os processos de construção da informação. Tradução de Marcel Aristides Ferrada Silva. São Paulo: Cengage Learning, 2015.

ROQUE, Tatiana; CARVALHO, João B. P. História da Matemática. Coleção Profmat. Rio de Janeiro: SBM, 2012.

SBM. SOCIEDADE BRASILEIRA DE MATEMÁTICA. Profmat, 2017. Disponível em http://www.Profmat-sbm.org.br/. Acesso em 23/05/2017.

SCHUBRING, Gert. A noção de multiplicação: um "obstáculo" desconhecido na História da Matemática. Boletim de Educação Matemática (BOLEMA). Rio Claro (SP), ano 15, n. 18, p. $26-52,2002$.

SHULMAN, L. S. Knowledge and teaching: foundations of the new reform. Harvard Educational Review, Cambridge, v. 57, n. 1, p. 1-22, 1987. 